\title{
Pulmonary vasodilator therapy in the Fontan circulation: A world of uncertainties...
}

\author{
David Kalfa, MD, PhD
}

\footnotetext{
From the Division of Cardiac, Thoracic and Vascular Surgery, Section of Pediatric and Congenital Cardiac Surgery, Morgan Stanley Children's Hospital-New-York Presbyterian, Columbia University Medical Center, New York, NY.

Disclosures: Author has nothing to disclose with regard to commercial support.

Received for publication March 3, 2017; accepted for publication March 10, 2017; available ahead of print April 8, 2017

Address for reprints: David Kalfa, MD, PhD, Pediatric Cardiac Surgery, Morgan Stanley Children's HospitalNew-York Presbyterian, Columbia University Medical Center, New York, NY (E-mail: dk2757@cumc. columbia.edu).

J Thorac Cardiovasc Surg 2017;153:1466-7

$0022-5223 / \$ 36.00$

Copyright (c) 2017 by The American Association for Thoracic Surgery

http://dx.doi.org/10.1016/j.jtcvs.2017.03.029
}

This study by Agnoletti and colleagues ${ }^{1}$ aims at assessing the impact of a 6-month treatment by endothelin receptor antagonists (ERAs) on both hemodynamic and functional parameters in patients with Fontan circulation and increased pulmonary vascular resistance (PVR).

The Fontan physiology could be a good target for ERAs, because even a slight increase in PVR may compromise the "no-pump-driven" pulmonary circulation. The effects of ERAs on the functional capacity and hemodynamic in the population undergoing the Fontan are still controversial. In 2014, a randomized, placebocontrolled, double-blind trial ${ }^{2}$ showed that ERAs improve exercise capacity in adolescents and adults after the Fontan operation. This was in direct contrast to a previous open-label trial of bosentan in adult patients undergoing the Fontan, showing no functional improvement. ${ }^{3}$ A systematic review by Oldenburger and colleagues ${ }^{4}$ of studies published between 1997 and 2014 concluded that ERAs may improve exercise capacity at the short term, but given the low level of scientific evidence of these studies, the results need to be interpreted carefully, explaining why ERAs are not routinely and widely used in patients undergoing the Fontan.

Agnoletti's group ${ }^{1}$ tackled this controversial topic by investigating the potential effects of ERAs in pediatric, adolescent, and adult patients undergoing the Fontan with PVR greater than $2 \mathrm{Wu}^{*} \mathrm{~m}^{2}$ using cardiac catheterization and cardiopulmonary testing. They showed a populationdependent impact of ERAs, with a significant decrease of PVR in all patients, an improvement in New York Heart Association class and cardiac index in adolescents and adults, and significant functional improvement (ventilatory capacity and oxygen consumption) in adolescents, thus suggesting that pulmonary vasodilatation with ERAs might be useful in selected patients undergoing the Fontan with increased PVR.

Nevertheless, this study has some significant limitations. This study does not have a control group, is a small and

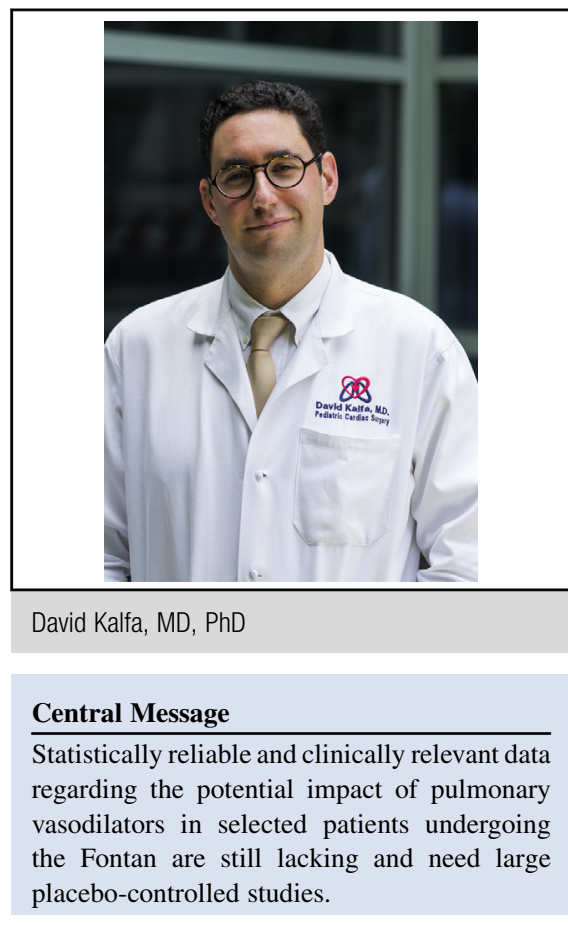

See Article page 1468.

heterogeneous series (different ERAs investigated in different age groups and 8 patients per group only), and has a short follow-up. Moreover, the impact of the associated hemodynamic lesions on the hemodynamic and functional change observed during the course of this 6-month study probably is underestimated and may represent a confounder in the series. Finally, the clinical significance and impact on quality of life of these statistically significant hemodynamic and functional change remain to be proven. Despite these limitations, this article ${ }^{1}$ is definitely of interest and hypothesis generating.

Given the high number of possible confounders and the physiologic heterogeneity in the population undergoing the Fontan, large multicentric placebo-controlled studies focusing on selected subgroups of patients undergoing the Fontan with a long follow-up are definitely needed to bring statistically reliable and clinically relevant answers about the long-term effects of ERAs in Fontan subjects, patient selection, treatment window, and doses. Mechanistically oriented basic science research programs assessing the physiologic effects of ERAs in large animal models of Fontan circulation at the cellular, molecular, 
and genetic levels will be needed to clear up our clinical uncertainties.

\section{References}

1. Agnoletti G, Gala S, Ferroni F, Bordese R, Appendini L, Napoleone CP, et al. Endothelin inhibitors lower pulmonary vascular resistances and improve functional capacity in patients with Fontan Circulation. $J$ Thorac Cardiovasc Surg. 2017;153:1468-75.
2. Hebert A, Mikkelsen UR, Thilen U, Idorn L, Jensen AS, Nagy E, et al. Bosentan improves exercise capacity in adolescents and adults after Fontan operation. Circulation. 2014;130:2021-30.

3. Schuuring MJ, Vis JC, van Dijk AP, van Melle JP, Vliegen HW, Pieper PG, et al Impact of bosentan on exercise capacity in adults after the Fontan procedure: a randomized controlled trial. Eur J Heart Fail. 2013;15:690-8.

4. Oldenburger NJ, Mank A, Etnel J, Takkenberg JJM, Helbing WA. Drug therapy in the prevention of failure of the Fontan circulation: a systematic review. Cardiol Young. 2016;26:842-50. 